\title{
KAJIAN PELAKSANAAN PENYEDIAAN UTILITAS UMUM PERKOTAAN TERPADU KABUPATEN TEMANGGUNG
}

\section{STUDY OF INTEGRATED PUBLIC UTILITY PROVISION IN TEMANGGUNG REGENCY}

\author{
Sri Kumala Parahyang Sari', Iwan Rudiarto ${ }^{2}$ \\ ${ }^{1}$ Magister Pembangunan Wilayah dan Kota; Universitas Diponegoro; jeannekumala@gmail.com \\ 2Departemen Perencanaan Wilayah dan Kota; Universitas Diponegoro, Semarang, Jawa Tengah; irudiarto@yahoo.com
}

Info Artikel:

- Artikel Masuk: 03/04/18

- Artikel diterima: 03/07/18

- Tersedia Online: 24/08/18

\begin{abstract}
ABSTRAK
Dalam memenuhi pelayanan untuk masyarakatnya, maka sebuah kota terus melakukan pembangunan dan penambahan pada bagian infrastruktur terutama pada penyediaan utilitas umumnya. Kabupaten Temanggung mengalami peningkatan jumlah penduduknya tiap tahun. Hal ini membuat pemerintah daerah perlu melakukan perencanaan pembangunan serta perbaikan pada utilitas umum yang ada. Dalam penyediaan pembangunann utilitas umum menimbulkan permasalahan berupa galian utilitas umum yang tumpang tindih. Fenomena ini terjadi dikarenakan pelaksanaan penyediaan utilitas umum masih belum terintegrasi. Berdasarkan hal-hal tersebut menimbulkan pertanyaan bagaimana pelaksanaan penyediaan utilitas umum perkotaan di Kabupaten Temanggung? Tujuan dari penelitian ini untuk melakukan pengkajian terhadap pelaksanaan penyediaan utilitas umum. Variabel penelitian yang dimaksud adalah komunikasi, kesadaran, kompetisi partisipan, kesepakatan, komitmen dan insentif koordinasi serta kontinuitas perencanaan. Metode penelitian ini adalah metode kualitatif. Setelah dilakukan penilaian pada tiap indikator, diketahui bahwa koordinasi yang terjadi antar instansi dalam SKPD cukup kuat. Hubungan koordinasi yang bersifat sedang ada pada hubungan antar SKPD - non SKPD dan instansi dalam SKPD - masyarakat. Selain itu hubungan koordinasi yang bersifat lemah terjadi pada hubungan antara instansi non SKPD - non SKPD dan non SKPD - masyarakat. Selain itu tiap aspek koordinasi memiliki besaran keterkaitan yang berbeda dengan aspek yang lainnya.
\end{abstract}

Kata Kunci : Pembangunan Utilitas Umum, Infrastruktur, Integrasi, Koordinasi, Komunikasi, Kabupaten Temanggung

\section{ABSTRACT}

In fulfilling the services for its people, a city continues to make development and addition to the infrastructure sector, especially in the provision of public utilities. Temanggung Regency has increased its population every year. This makes local governments need to do development planning as well as improvements to existing public utilities. In the provision of public utilities development, it raises the issue of overlapping public utility excavations. This phenomenon occurs because the implementation of public utilities is still not integrated. Based on these matters raises the question how the implementation of management of urban public utilities in Temanggung Regency. The purpose of this study is to assess the implementation of public utilities management. The variables are communication, awareness, participant competition, agreement; commitment and incentive coordination and continuity of planning. The method of this research is qualitative method. After the assessment on each indicator, it is known that the coordination between institutions in SKPD is quite strong. Medium coordination relationship exists in the relationship between SKPD - non SKPD and agencies in SKPD community. In addition, the weak coordination relationship occurs in the relationship between non-SKPD agencies - non SKPD and non SKPD - community. In addition, each aspect of coordination has a number of relationships that are different from other aspects.

Keyword: Development of Public Utilities, Infrastructure, Integration, Coordination, Communication, Temanggung Regency

Copyright (๑) 2018 JPWK-UNDIP This open access article is distributed under a Creative Commons Attribution (CC-BY-NC-SA) 4.0 International license.

Cara men-sitasi (APA 6th Style):

Parahyang Sari, Sri Kumala., \& Rudiarto, Iwan. (2018). Kajian Pelaksanaan Penyediaan Utilitas Umum Perkotaan Terpadu Kabupaten Temanggung. Jurnal Pembangunan Wilayah dan Kota, Vol 14 (2), 123-130 


\section{PENDAHULUAN}

Pertumbuhan suatu kota dapat ditandai dengan meningkatnya jumlah penduduk secara terus menerus yang mengakibatkan meningkatnya aktivitas sosial dan ekonomi pada kota tersebut. Peningkatan aktivitas sosial dan ekonomi tersebut harus berbanding lurus dengan peningkatan pembangunan infrastruktur yang berguna sebagai penunjang aktivitas sosial dan ekonomi, karena infrastruktur perkotaan merupakan turunan tata ruang kota yang bertujuan untuk memfasilitasi warga kota dalam menjalankan aktivitasnya. Sistem infrastruktur dapat didefinisikan sebagai fasilitas-fasilitas atau struktur-struktur dasar, peralatan-peralatan, instalasi-instalasi yang dibangun dan yang dibutuhkan untuk berfungsinya sistem sosial dan sistem ekonomi masyarakat (Grigg, 2000). Pembangunan infrastruktur dapat digunakan sebagai insentif pertumbuhan kegiatan ekonomi serta alat kontrol untuk kelestarian lingkungan dan efisiensi (Dep.PU, 1998). Kesuksesan dan kemajuan dari masyarakat tergantung dari infrastruktur fisik untuk mendistribusikan sumber daya dan layanan penting untuk publik (Uddin,et all, 2013). Grig (1988, dalam Sucipto dkk) mengatakan bahwa infrastruktur mengacu pada penyediaan sistem fisik seperti transportasi, irigasi, drainase bangunan gedung dan fasilitas umum lainnya yang dibutuhkan guna memenuhi kebutuhan dasar masnusia dalam bidang sosial dan ekonomi. Sistem infromasi merupakan fungsi pendukung utama dari sistem sosial dan ekonomi dalam kehidupan sehari-hari masyarakat. Beberapa contoh infrastruktur publik yang dibangun oleh pemerintah, yaitu jalan, bandara, stasiun, gorong-gorong, kantor polisi, dan berbagai infrastruktur publik lainnya. Berikut adalah jenis infrastrukturnya: (1) Infrastruktur keras adalah infrastruktur yang memiliki bentuk fisik nyata dan kegunaannya berasal dari bentuk fisiknya; (2) Infrastruktur keras yang non-fisik adalah infrastruktur perangkat keras yang tidak memiliki bentuk fisik yang nyata / nyata namun berguna dan mendukung adanya infrastruktur keras lainnya; (3) Definisi soft infrastructure adalah infrastruktur berupa kerangka kelembagaan atau kelembagaan.

Perkembangan sosial dan kegiatan ekonomi tidak dapat berjalan dengan lancar jika tidak memiliki kesinambungan antara prasarana dan sarana dengan ketersediaan utilitas umum seperti air bersih, telepon, listrik, dan sebagainya. Maka, penyediaan utilitas umum penting untuk diperhatikan guna mensukseskan pembangunan setiap lembaga sosial dan sektor kehidupan ekonomi yang ada di masyarakat. Dalam pelaksanaan penyediaan utilitas umum perkotaan terkesan tumpang tindih dan tanpa koordinasi antar pemangku kepentingan bahkan antar instansi satu dengan lainnya ada kecenderungan saling menyalahkan, seperti yang terjadi pada kasus di Kabupaten Temanggung dimana Bappeda memprotes dan memberhentikan galian jalan untuk instalasi kabel serat optik dari TELKOM karena dianggap tidak berijin dan ilegal, kemudian Badan Cipta Karya mengatakan pipa PDAM mengganggu saluran drainase. Hal - hal di atas menunjukkan tidak adanya keterpaduan dalam pelaksanaan penyediaan utilitas umum perkotaan. Tidak adanya keterpaduan pelaksanaan penyediaan utilitas umum ini memperpanjang rantai birokrasi dan menyebabkan inefisiensi pelaksanaan penyediaan utilitas umum perkotaan (dari segi keselamatan pengguna jalan, waktu dan cara pengerjaan) yang pada akhirnya menyebabkan anggaran yang harus dikeluarkan menjadi lebih besar. Sangat diperlukan pelaksanaan penyediaan utilitas umum perkotaan dengan perencanaan yang matang, komprehensif, dan terpadu untuk mereduksi munculnya permasalahan-permasalahan akibat disintegrasi tersebut.

Keterpaduan sendiri memiliki pengertian berupa sebuah situasi suatu kondisi yang menjadi satu atau menyatu saling terpadu sedangkan Koordinasi adalah perihal mengatur suatu organisasi atau kegiatan sehingga peraturan dan tindakan yang akan dilaksanakan tidak saling bertentangan atau simpang siur, atau ringkasnya koordinasi adalah suatu kegiatan atau tindakan dari keterpaduan. Selain itu menurut G.R Terry dalam Hasibuan (2006: 85), Koordinasi adalah suatu kondisi yang tertib dalam upaya untuk menciptakan kondisi harmonis dan tindakan terpadu untuk tujuan lain. Dari kedua pengertian tersebut maka dapat disimpulkan bahwa untuk mencapai suatu kondisi yang terpadu diperlukan suatu tindakan yaitu berupa koordinasi. Oleh karena itu dalam penelitian ini menggunakan beberapa indikator koordinasi yang diharapkan dengan adanya koordinasi maka dapat mencapai keterpaduan tersebut. 
Dari permasalahan yang telah dijabarkan di atas, perlunya perumusan permasalahan yang jelas terkait fenomena disintegrasi dari penyediaan utilitas umum di wilayah perkotaan, serta dampak-dampak turunannya yang dipicu atau disebabkan oleh adanya fenomena tersebut. Sehingga dalam studi ini, pertanyaan yang akan dijawab adalah: Bagaimana pelaksanaan penyediaan utilitas umum perkotaan terpadu di Kabupaten Temanggung? Tujuan dari penelitian ini adalah untuk melakukan pengkajian terhadap pelaksanaan penyediaan utilitas umum perkotaan terpadu di Kabupaten Temanggung. Harapan dari penelitian adalah dapat menjadi pertimbangan pemerintah agar tidak terjadi tumpang tindih dalam pelaksanaan penyediaan utilitas umum didalam Kabupaten Temanggung.

Perbedaan penelitian ini dengan beberapa penelitian yang terdahulu adalah terletak pada fokus pembahasannya hanya pada hard infrastructure perkotaan saja. Selain itu penelitian ini tidak hanya membahas bentuk koordinasi yang terjadi, namun besarnya koordinasi yang ada antar instansi juga menjadi fokus penelitian ini. Keluaran pada penelitian ini berupa rekomendasi pelaksanaan pengelolaan penyediaan utilitas umum perkotaan terpadu di Kabupaten Temanggung diharapkan dapat membantu pemerintah dalam melakukan manajemen pengeolaan infrastruktur di perkotaan Temanggung agar lebih efisien dan tepat sasaran. Untuk memperjelas masalah yang akan dibahas dan agar tidak terjadi pembahasan yang meluas atau menyimpang,maka perlu kiranya dibuat batasan masalah. Ruang lingkup materi Ruang lingkup penelitian mengenai Pelaksanaan Penyediaan Utilitas Umum Perkotaan Terpadu di Kabupaten Temanggung ini nantinya hanya akan berfokus pada infrastruktur keras non fisik atau infrastruktur yang tidak memiliki bentuk nyata namun berguna dan mendukung infrastruktur keras lainnya. Infrastruktur non fisik erat kaitannya dengan utilitas umum yang mana pada penelitian akan lebih difokuskan lagi pada beberapa utilitas umum yaitu jalan (DPU), air bersih (PDAM), ketenagalistrikan (PLN), dan telekomunikasi (TELKOM). Demi menjaga fokus bahasan penelitian ini akan menggunakan lima indikator koordinasi yang baik (Handayaningrat, 1989 dalam Kusumayanti, 2014). Kelima indikator atau aspek tersebut disesuaikan dengan ketersediaan data dan kondisi eksisting, yaitu : (1) aspek komunikasi, (2) aspek kesadaran pentingnya koordinasi, (3) aspek kompetisi partisipan, (4) aspek kesepakatan, komitmen, dan insentif koordinasi, serta (5) aspek kontinuitas perencanaan.

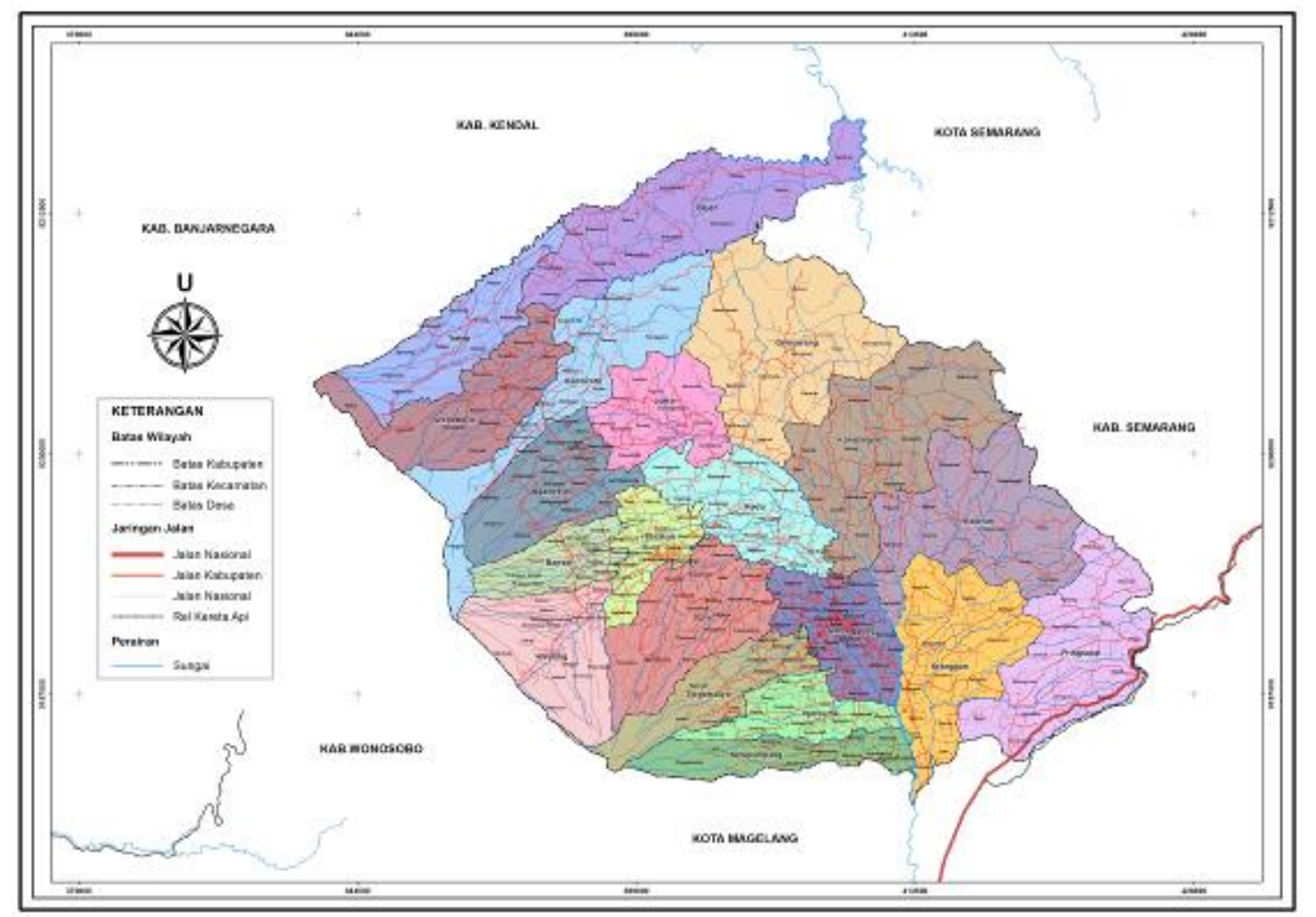

Gambar 1. Peta Wilayah Studi (Bappeda Temanggung, 2016) 
Ruang lingkup wilayah yang diambil dalam penelitian ini adalah Kabupaten Temanggung. kabupaten Temanggung secara astronomis terletak diantara 110023'-110046'30" bujur Timur dan 7014'-7032'35" Lintang Selatan dengan luas wilayah 870,65 km2 (87.065 Ha). Batas-batas administrative Kabupaten Temanggung adalah sebagai berikut (terlihat dalam Gambar 1):

- Utara :berbatasan dengan Kabupaten Kendal dan Kabupaten Semarang

- Timur :berbatasan dengan Kabupaten Semarang dan Kabupaten Magelang

- Selatan :berbatasan dengan Kabupaten Magelang

- Barat :berbatasan dengan Kabupaten Wonosobo.

\section{DATA DAN METODE}

\subsection{Metodologi}

Ditinjau dari jenis datanya pendekatan penelitian yang digunakan dalam penelitian ini adalah pendekatan kualitatif. Adapun jenis pendekatan penelitian ini adalah deskriptif. Jenis penelitian deskriptif kualitatif yang digunakan pada penelitian ini dimaksudkan untuk memperoleh informasi mengenai kajian bentuk penyediaan dan pengelolaan utilitas umum perkotaan terpadu di Kabupaten Temanggung secara mendalam dan komprehensif. Selain itu, dengan pendekatan kualitatif diharapkan dapat diungkapkan situasi dan permasalahan yang dihadapi dalam kegiatan ini. Dalam metode kualitatif, data yang diperoleh berupa narasi yang diungkapkan oleh narasumber yang memiliki pengetahuan tentang data yang kita butuhkan. Data tersebut nantinya mampu menjawab pertanyaan penelitian.

Sedangkan untuk metod analisis yang digunakan dalam penelitian ini memiliki dua tahapan, yaitu sebagai berikut:

1. Mengidentifikasi bentuk koordinasi dalam pelaksanaan pengelolaan penyediaan utilitas umum di Kabupaten Temanggung.

Identifikasi ini bertujuan untuk mengidentifikasi bentuk dari koordinasi dalam pengelolaan penyediaan utilitas umum di kabupaten temanggung. Identifikasi dilakukan dengan melihat aktoraktor yang terlibat dimana dalam hal ini adalah instansi penyedia utilitas umum yaitu PLN, PDAM, BAPPEDA, DPU. Perolahan data dilakukan dengan melakukan wawancara dan observasi pada instansi dan lokasi penelitian. Hasil dari identifikasi ini diharapkan dapat membantu dalam menetukan potensi permasalahan maupun peluang yang akan di analisis pada tahap selanjutnya. Analisis ini menggunakan analisis deskriptif kualitatif.

2. Analisis kualitatif deskriptif kondisi internal dan eksternal pengelolaan penyediaan utiliitas umum perkotaan terpadu.

Dalam analisis ini bertujuan untuk mengetahui point-point strategi yang dimiliki Kabupaten Temanggung dalam pengelolaan penyediaan utilitas umum perkotaan. Untuk mendapatkan hasil tersebut dalam analisi ini menggunakan data hasil analisis koordinasi berdasarkan indikator atau variabel yang digunakan (5 variabel), yaitu kondisi internal dan eksternal dalam penyediaan pengelolaan penyediaan utlitas umum perkotaan di Kabupaten Temanggung.

2.2. Variabel yang Digunakan

Adapun variabel atau aspek yang digunakan dalam peneltian ini sesuai dengan yang disampaikan oleh Handayaningrat, 1989 dalam Kusumayanti, 2014. Variabel terebut adalah komunikasi, kesadaran pentingannya koordinasi, kompetensi partisipan, kesepaktan, komitmen dan insentif, serta kontinuitas perencanaan. Berikut adalah penjelasan dari masing-masing aspek : 
1. Aspek Komunikasi

Pada aspek komunikasi bertujuan untuk mengetahui ada atau tidaknya informasi untuk melakukan koordinasi, seperti apa alur informasi yang beredar, dan yang terakhir adalah teknologi yang digunakan untuk koordinasi seperti website dll.

2. Aspek Kesadaran Pentingnya Koordinasi

Tujuan dari aspek kesadaran pentingnya koordinasi adalah untuk melihat kesadaran para pelaku koordinasi, oleh karena itu akan menggunakan dua indikator. Pertama, tingkat pengetahuan pelaksana dalam koordinasi untuk melihat apakah dalam berkoordinasi sudah melibatkan tenaga ahli sehingga hasilnya implementasi program lebih optimal. Kedua, tingkat ketaatan terhadap hasil koordinasi, tujuannya untuk melihat kepatuhan para pelaku terhadap kesepatan yang telah dibuat.

3. Kompetensi Partisipan

Kompetensi partisipan berguna untuk mengetahui kemampuan para pelaku dalam melaksanakan kegiatan dari masing-masing instansi. Dalam aspek ini menggunakan dua indikator yaitu ada tidaknya pejabat yang berwenang untuk terlibat dan ada tidaknya ahli dibidang pembangunan yang terlibat.

4. Kesepatan, Komitmen dan Insentif Koordinasi

Pada aspek ini menggunakan emapt indikator yang secara umum untuk mengetahui tingkat persetujuan dari instansi-instansi yang terlibat. Keempat aspek tersebut adalah ada tidaknya bentuk kesepakatan, ada tidaknya pelaksana kegiatan, ada tidaknya sanksi bagi pelanggar kesepakatan dan ada tidaknya insentif bagi pelaksana koordinasi.

5. Kontinuitas Perencanaan

Aspek kontinuitas merupakan aspek yang bertujuan untuk melihat feedback dari hasil kesepakatan yang telah dibuat. Dalam aspek ini menggunakan dua indikator, yaitu ada tidaknya umpan balik dari obyek dan subyek pambangunan dan ada tidaknya perubahan terhadap hasil kesepakatan.

\section{HASIL DAN PEMBAHASAN}

Dari hasil analisis berdasarkan data yang telah terkumpul, pembahasan menganai hasil analisis akann lebih memfokuskan pada tipologi yang terbentuk dari adanya analisis koordinasi infrastruktur di Kabupaten Temanggung. Dalam pembahasan ini dibagi kedalam dua hal yaitu pembahasan terkait analisis tipologi antar instansi pembangunan utilitas umum di Kabupaten Temanggung dan analisis tipologi koordinasi berdasarkan variabel yang digunakan. Berikut ini adalah pembahasan lebih lanjut ke tiga hal tersebut.

\subsection{Analisis Tipologi Koordinasi Antar Instansi Pembangunan Utilitas Umum di Kabupaten Temanggung}

Setelah dilakukan analisis pervariable koordinasi pada sub bab sebelumnya, kemudian dari hasil wawancara yang telah dijabarkan didapatkan kesimpulan hubungan koordinasi yang ada pada tiap-tiap instansi baik itu dalam SKPD, luar SKPD dan masyarakat. Adanya hubungan tersebut kemudian terbentuklah suatu tipologi koordinasi di Kabupaten Temanggung dalam pembangunan utilitas berikut ini.

Tabel 1 Nilai Koordinasi Perinstansi Di Kabupaten Temanggung (Hasil Analisis, 2018)

\begin{tabular}{|c|r|r|r|r|r|r|}
\hline & BAPPEDA & \multicolumn{1}{|c|}{ DPU } & PLN & \multicolumn{1}{|c|}{ PDAM } & TELKOM & Masyarakat \\
\hline BAPPEDA & & 3 & 2 & 2 & 2 & 2 \\
\hline DPU & & & 2 & 2 & 2 & 2 \\
\hline PLN & & & & 1 & 1 & 1 \\
\hline PDAM & & & & & 1 & 1 \\
\hline TELKOM & & & & & 1 \\
\hline
\end{tabular}




\begin{tabular}{|l|l|l|l|l|l|l|}
\hline & BAPPEDA & DPU & PLN & PDAM & TELKOM & Masyarakat \\
\hline Masyarakat & & & & & & \\
\hline
\end{tabular}
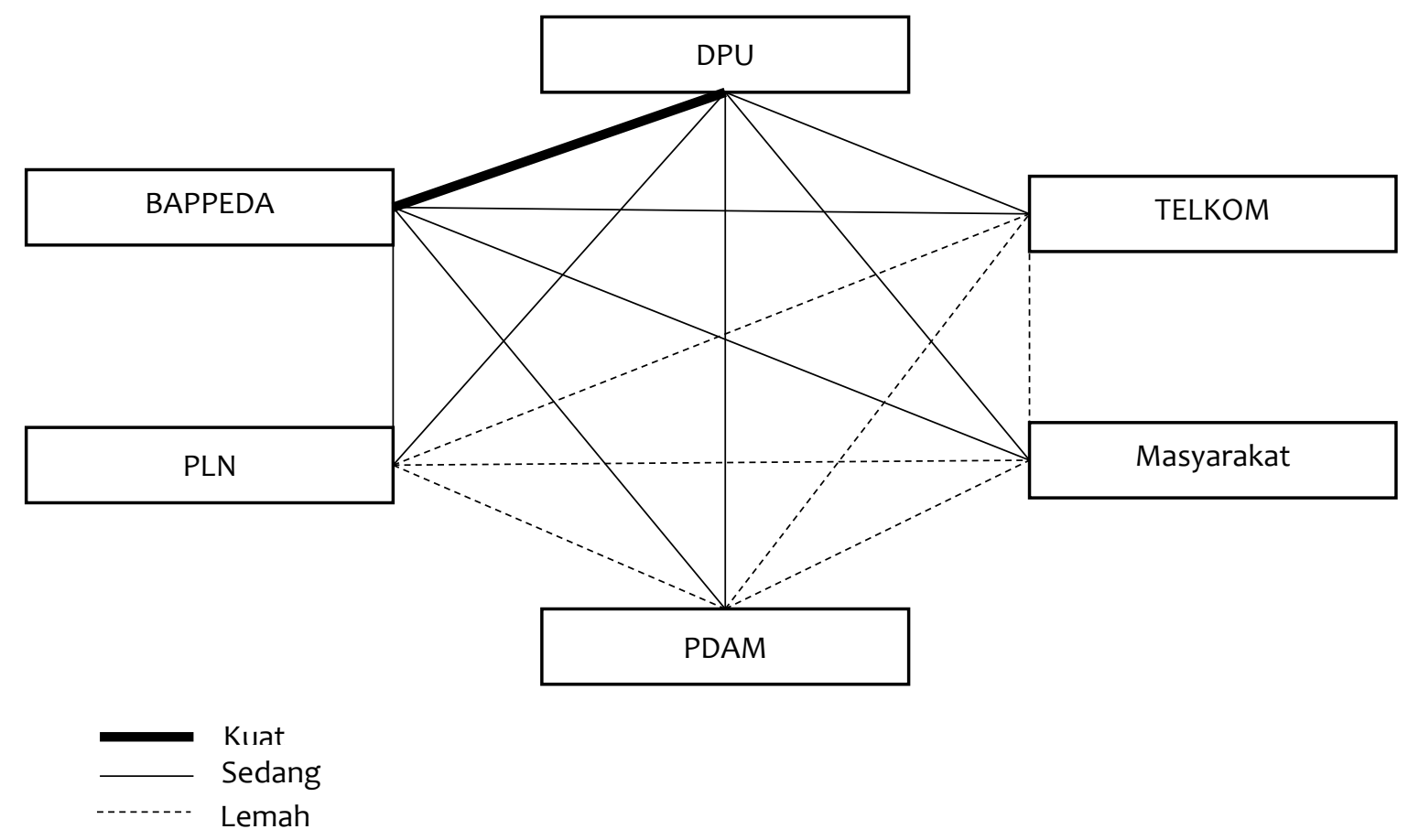

Gambar 2 Tipologi Koordinasi Kabupaten Temanggung (Hasil Analisis, 2018)

Berdasarkan bagan yang ada di atas, dapat dilihat hubungan koordinasi antar instansi baik instansi dalam dan luar SKPD. Hubungan koordinasi ini ada yang bersifat kuat, sedang dan lemah. Hubungan koordinasi yang terjadi antar instansi atau aktor dalam suatau sistem didapatkan dari hasil wawancara pada beberapa narasumber yang mewakili tiap instansi. Dalam hal ini dapat disimpulkan bahwa koordinasi yang terjadi antar instansi yang ada dalam SKPD cukup kuat, dibuktikan dengan sudah adanya pertemuan rutin yang membahas masalah pembangunan dan perencanaan utilitas antar instansi dalam SKPD. Namun adanya hubungan koordinasi yang kuat tersebut masih belum sempurna, tidak adanya sanksi dan evaluasi yang menjadikan koordinasi hanya bersifat sementara. Selain itu komitmen antar pelaku koordinasi juga dirasa masih kurang.

\subsection{Analisis Tipologi Koordinasi Berdasarkan Variabel yang Digunakan}

Analisis berikut merupakan tahapan lanjutan, pada analisis berikut akan diberikan nilai secara kualitatif yang mewakili kekuatan dari tiap indikator koordinasi. Nilai diberikan berdasarkan asumsi peneliti dari hasil wawancara dengan instansi terkait. Berikut adalah penilaian dari tiap indikator dan keterangan atau alasan pemilihan skor tersebut:

Tabel 2 Hubungan Koordinasi Pervariabel Di Kabupaten Temanggung (Hasil Analisis, 2018)

\begin{tabular}{|l|l|l|}
\hline No & \multicolumn{1}{|c|}{ Variabel } & \multicolumn{1}{c|}{ Keterangan } \\
\hline 1 & Komunikasi (KK) & $\begin{array}{l}\text { Informasi yang terjadi sangat kuat ditandai dengan adanya } \\
\text { informasi yang diberikan dan adanya website untuk } \\
\text { mengakses tersebut, walaupun masih belum memiliki alur } \\
\text { yang paten. }\end{array}$ \\
\hline 2 & Kesadaran (KS) & $\begin{array}{l}\text { Masih kurangnya tingkat kesadaran atau kepedulian pada } \\
\text { koordinasi karena masih belum adanya pengaturan- } \\
\text { pengaturan yang dilakukan atau yang ada dalam satu }\end{array}$ \\
\hline
\end{tabular}




\begin{tabular}{|l|l|l|}
\hline No & \multicolumn{1}{|c|}{ Variabel } & \multicolumn{1}{c|}{ Keterangan } \\
\hline 3 & Kompetensi partisipan (KP) & $\begin{array}{l}\text { Partisipan atau aktor-aktor koordinasi masih kurang karena } \\
\text { kemampuan atau keahlian para ahli masih perlu } \\
\text { ditingkatkan, hal tersebut dapat dilihat dari instansi SKPD } \\
\text { belum adanya databse pelaksanaan pengelolaan } \\
\text { penyediaan utlitas, dari non SKPD masih ada masterplan } \\
\text { dan perawatan utilitas, dll. }\end{array}$ \\
\hline 4 & $\begin{array}{l}\text { Kesepakatan, komitmen dan } \\
\text { insentif (KKI) }\end{array}$ & $\begin{array}{l}\text { Kesepakatan yang dilakukan hanya secara sepihak, hal } \\
\text { terebut dikarenakan keputusan instansi non skpd tetap dari } \\
\text { pusat (bukan daerah). Akan tetapi dalam skpd, hal } \\
\text { kesepatan, komitmen, dan insentif sudah berjalan dengan } \\
\text { dengan baik namun belum ada sanksi yang mengatur } \\
\text { kesepakatan. }\end{array}$ \\
\hline 5 & $\begin{array}{l}\text { Kontinuitas perencana } \\
\text { (KPR) }\end{array}$ & $\begin{array}{l}\text { Dalam indikator kontinuitas masih kurang karena belum } \\
\text { adanya evaluasi yang dilakukan baik dari dalam skpd } \\
\text { maupun luar skpd. }\end{array}$ \\
\hline
\end{tabular}

Tabel 3 Nilai Koordinasi Antar Variabel Di Kabupaten Temanggung (Hasil Analisis, 2018)

$$
\begin{array}{ll}
\text { Keterangan : } \\
=\quad: \text { Setara } \\
>\quad: \text { Dominan } \\
>\quad: \text { Sangat Dominan }
\end{array}
$$

\begin{tabular}{|c|c|c|c|c|c|}
\hline & KK & KS & KP & KKI & KPR \\
\hline KK & & $>$ & $>$ & $>>$ & $>$ \\
\hline KS & & & $=$ & $>$ & $=$ \\
\hline KP & & & & $=$ & $=$ \\
\hline KKI & & & & & $>$ \\
\hline KPR & & & & & \\
\hline
\end{tabular}

Berdasarkan hasil analisis dan wawancara kepada beberapa narasumber maka didapatkan penilaian pada tiap aspek koordinasi. Matriks diatas menandakan bahwa sebenarnya sudah ada bentuk koordinasi sebagai wujud keterpaduan pada pembangunan utilitas di kabupaten temanggung, namun koordinasi yang ada masih belum cukup kuat untuk mewujudkan keterpaduan perencanaan khususnya dalam hal pembangunan utilitas.

Setelah dilakukan penilaian pada tiap indikator, maka dapat dilihat pula nilai keterkaitan antar variabel koordinasi. Tiap aspek koordinasi memiliki besaran keterkaitan yang berbeda dengan aspek yang lainnya. Berdasarkan hasil keterkaitan dengan beberapa aspek lainnya, dapat disimpulkan bahwa koordinasi yang sudah ada perlu ditingkatkan pada beberapa hal agar koordinasi yang ada di Kabupaten Temanggung dapat berjalan dengan baik sehingga dapat mencapai tujuan yaitu keterpaduan pada sistem utilitas di daerah tersebut.

\section{KESIMPULAN}

Setelah dilakukan penilaian pada tiap indikator, dapat disimpulkan bahwa koordinasi yang terjadi antar instansi yang ada dalam SKPD cukup kuat, dibuktikan dengan sudah adanya pertemuan rutin yang membahas masalah pembangunan dan perencanaan utilitas antar instansi dalam SKPD. Untuk hubungan koordinasi yang bersifat sedang umumnya ada pada hubungan antar SKPD dengan non SKPD dan instansi dalam SKPD dengan masyarakat. Selain itu hubungan koordinasi yang bersifat lemah terjadi pada hubungan antara instansi non SKPD dengan non SKPD dan non SKPD dengan masyarakat. Selain itu dapat dilihat pula nilai keterkaitan antar variabel koordinasi. Tiap aspek koordinasi memiliki besaran keterkaitan yang berbeda dengan aspek yang lainnya. Berdasarkan hasil analisis, maka dapat disimpulkan bahwa 
pelaksanaan pengelolaan penyediaan utilitas umum perkotaan di Kabupaten Temanggung masih kurang terpadu. Hal tesebut dikarenakan komunikasi antara instansi masih lemah, koordinasi masih bersifat tentatif, tiap instansi belum memiliki perencanaan yang matang khususnya dalam pembangunan utilitas, dan belum adanya evaluasi dan sanksi dari hasil koordinasi yang telah dilakukan dalam SKPD.

Berikut ini terdapat beberapa rekomendasi strategi berdasarkan hasil temuan studi dilihat dari tingkat urgensinya guna mengatasi ketidakterpaduan dalam penyediaan utilitas umum di Kabupaten Temanggung antara lain:

- DPU sebagai instnasi SKPD yang memiliki wewenang sebagai leading sector perlu untuk membuat sanksi yang jelas bagi pelanggar yang melakukan kegiatan penyediaan maupun perbaikan utilitas umum.

- Koordinasi antara pemerintah dengan instansi-instansi terkait perlu diperkuat, terutama terkait pembagian prioritas pendanaan kegiatan dalam penyediaan utilitas umum.

- Masing-masing instansi khususnya non SKPD harus memiliki masterplan yang kemudian akan di sah (perda) kan oleh pemda, sehingga koordinasi dapat lebih bersifat preventif, tidak selalu bersifat tentatif yang selalu menunggu masalah datang baru ditindak lanjut.Bagi Pemerintah

- Diharapkan masyarakat dapat peduli akan pembangunan utilitas yang terjadi di daerah dengan cara ikut berpartisipatif pada setiap acara yang sengaja dilakukan pemerintah untuk mewadahi partisipasi masyarakatnya.

- Masyarakat juga ikut mengawasi pada pembangunan utilitas yang ada di daerahnya.

\section{REFERENSI}

Abdullah Syukur. 1987. KumpulanMakalah "Study Implementasi Latar Belakang Konsep Pendekatan dan Relevansinya Dalam Pembangunan". Persadi, Ujung Pandang. HIm 40

Adisasmita, Rahardjo. 2010. Pembangunan Kawasan dan Tata Ruang, Yogyakarta : Graha Ilmu.

Grigg, Neil S. 1988. Infrastructure engineering and management. Australia: John Wiley \& Sons.

Grigg, Neil S. 2000. "Grigg, Neil, \& Fontane G. Darrel, 2000. Infrastructure System Management \& Optimization. Internasional Seminar "Paradigm \& Strategy of Infrastructure Management" Civil Engineering Departement Dipononegoro University.

Kodoatie, Robert J. 2005. Pengantar Manajemen Infrastruktur. Yogyakarta: Pustaka Pelajar.

Kusumayanti, Dwi. 2014. "Koordinasi Antara Polisi Lalu Lintas, Dinas Perhubungan, Dan Satuan Polisi Pamong Praja Dalam Pengaturan Lalu Lintas Di Kota Bandar Lampung". Skripsi. FISIP Ilmu Pemerintahan, Universitas Lampung.

Moleong, Lexy J. (2007) Metodologi Penelitian Kualitatif, Penerbit PT Remaja Rosdakarya Offset, Bandung Nugroho, Bramasto. 2010. Pembangunan Kelembagaan Pinjaman Dana Bergulir Hutan Rakyat. JMHT, Vol. 16(3): 118-125.

Sucipto dkk. 2016. "Improving the Effectiveness of School Infrastructure Planning using Information Systems Based on Priority Scale in Salatiga". Skripsi. Uneversitas Negeri Semarang.

Uddin,Waheed, et all. 2013. Public Infrastructure Asset Management, Second Edition. New York : McGrawHill Education.

Purwo, Ageng. 2012. Kajian Teori Kebijakan Publik. (http://eprints.uny.ac.id/8530/3/BAB\%202\%20\%2007401241045.pdf Diunduh 8 Mei 2016.

http://sporttobe.blogspot.com/2010/06/pengertian-ruang.html, Diakses pada tanggal 26 Mei 2016 